\title{
Money is Brain: Financial Barriers and Consequences for Canadian Stroke Patients
}

\author{
Aravind Ganesh, Kathryn King-Shier, Braden J. Manns, Michael D. Hill, \\ David J.T. Campbell
}

\begin{abstract}
Background: Stroke patients of lower socioeconomic status have worse outcomes. It remains poorly understood whether this is due to illness severity or personal or health system barriers. We explored the experiences of stroke patients with financial barriers in a qualitative descriptive pilot study, seeking to capture perceived challenges that interfere with their poststroke health and recovery. Methods: We interviewed six adults with a history of stroke and financial barriers in Alberta, Canada, inquiring about their: (1) experiences after stroke; (2) experience of financial barriers; (3) perceived reasons for financial barriers; (4) health consequences of financial barriers; and (5) mechanisms for coping with financial barriers. Two reviewers analyzed data using inductive thematic analysis. Results: The participants developed new or worsened financial circumstances as a consequence of stroke-related disability. Poststroke impairments and financial barriers took a toll on their mental health. They struggled to access several aspects of long-term poststroke care, including allied health professional services, medications, and proper nutrition. They described opportunity costs and tradeoffs when accessing health services. In several cases, they were unaware of health resources available to them and were hesitant to disclose their struggles to their physicians and even their families. Conclusion: Some patients with financial barriers perceive challenges to accessing various aspects of poststroke care. They may have inadequate knowledge of resources available to them and may not disclose their concerns to their health care team. This suggests that providers themselves might consider asking stroke patients about financial barriers to optimize their long-term poststroke care.
\end{abstract}

RÉSUMÉ: Votre argent, votre cerveau : les obstacles financiers et les conséquences auxquels font face les patients canadiens victimes d'un AVC. Contexte: Les patients de statut socioéconomique inférieur victimes d'un AVC se distinguent par de moins bons pronostics de réadaptation. On comprend encore mal si cela est attribuable à la gravité de leur affection ou bien à des obstacles financiers personnels ou liés aux systèmes de santé. Dans le cadre d'une étude pilote qualitative de nature descriptive, nous avons ainsi voulu nous pencher sur les cas de patients victimes d'un AVC faisant face à des obstacles financiers. À cet égard, nous avons cherché à comprendre les difficultés qu'ils perçoivent et qui sont susceptibles de nuire à leur santé et à leur récupération post-AVC. Méthodes: Nous avons interviewé six adultes albertains (Canada) ayant des antécédents d'AVC et faisant face à des obstacles financiers. Nous avons cherché à nous enquérir de : (1) leurs expériences à la suite de leur AVC ; (2) de leur vécu en lien avec leurs obstacles financiers ; (3) des raisons qui, selon eux, expliquaient ces obstacles ; (4) des conséquences de ces obstacles sur leur santé ; (5) et des moyens à leur portée pour y faire face. Deux évaluateurs se sont ensuite penchés sur ces données au moyen d'une analyse thématique par raisonnement inductif. Résultats: Au dire des participants, ils ont commencé à éprouver des difficultés financières ou ont vu ces dernières s'aggraver en raison de l'invalidité consécutive à leur AVC. Leurs troubles post-AVC et leurs obstacles financiers ont aussi eu de graves répercussions sur leur santé mentale. Ils ont dû se démener pour avoir accès à des soins de longue durée post-AVC, ce qui inclut des services de santé connexes, des médicaments et une alimentation adéquate. Ils ont aussi décrit le manque à gagner et les compromis financiers au moment d'avoir accès à des services de santé. Dans bien des cas, ils ignoraient l'existence de ressources à leur disposition et étaient réticents à révéler leurs difficultés à leurs médecins et même à leurs familles. Conclusions: Certains patients aux prises avec des obstacles financiers considèrent l'accès à des soins post-AVC comme un défi. Il est possible qu'ils possèdent une connaissance réduite des ressources à leur disposition et qu'ils ne fassent pas part de leurs préoccupations à leur équipe soignante. Cela nous porte à croire que les dispensateurs de soins devraient eux-mêmes envisager de questionner les patients victimes d'un AVC au sujet de ces obstacles financiers, et ce, afin d'optimiser les soins de longue durée post-AVC leur étant prodigués.

Keywords: Stroke, Cerebrovascular disease, Communication, Doctor-patient relationship, Education, Financial barriers, Health services research, Outcomes research, Qualitative research, Quality of care

doi:10.1017/cjn.2016.411

Can J Neurol Sci. 2017; 44: 146-151

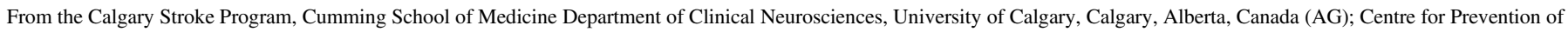

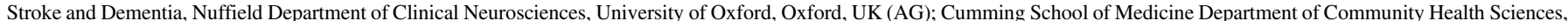

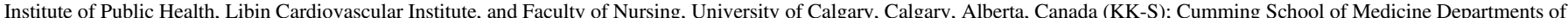

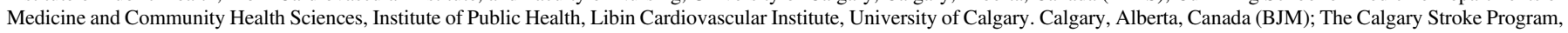

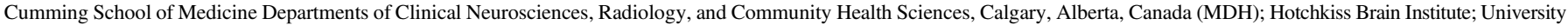

of Calgary. Calgary, Alberta, Canada (MDH); Cumming School of Medicine Departments of Medicine and Community Health Sciences, University of Calgary, Alberta, Canada (DJTC) Received February 14, 2016. Final Revisions Submitted April 25, 2016. Date of Acceptance May 22, 2016.

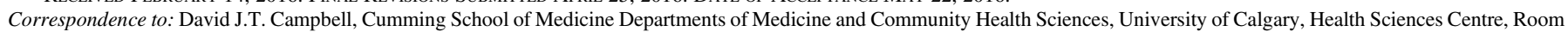
G236. 3330 Hospital Dr NW, Calgary, Alberta, Canada, T2N 4N1. Email: dcampbel@ucalgary.ca 
Cohort studies in England and Canada have demonstrated lower survival rates after an index stroke in patients of lower socioeconomic status, even after adjustment for age, sex, stroke risk factors, severity, and processes of acute care. ${ }^{1,2}$ In countries with universal health care systems, one might not expect financial barriers to be a significant factor in treatment, compared with systems like the United States where median income has been shown to be a significant predictor of access to both urgent stroke treatments (i.e. thrombolytic agents) and follow-up preventive care or care in a high-volume hospital. ${ }^{3}$ This raises the question of what factors may be contributing to the observed differences in outcomes in these settings.

A recent retrospective cohort analysis of 11,050 patients with ischemic stroke or transient ischemic attack in Ontario sought to identify discrepancies in care provision, including postdischarge care. ${ }^{4}$ This study found little evidence of a care gap across income quintiles, with no difference detected in the use of postdischarge home care services or in adherence to antihypertensive, antithrombotic, or lipid-lowering medications. Yet another study that included stroke patients found that $10 \%$ to $20 \%$ of patients with chronic diseases perceive financial barriers to care for their condition; actual income may be less of an issue compared with perceived financial barriers to care. ${ }^{5}$

Although qualitative research may be underused in the neuroscience field, ${ }^{6}$ this type of study is the ideal methodology to address a gap in knowledge about the phenomenon of differential outcomes in stroke patients who perceive financial barriers to care. We sought to conduct a pilot study to explore the experiences of participants with financial barriers who had had a stroke, as well as their experiences of treatment and outcomes. The objective of this small pilot study was to get a sense of the types of financial barriers in this population to facilitate future examination of this problem.

\section{MethodS}

\section{Study Design and Sampling Strategy}

We report a qualitative descriptive analysis of participants with a history of stroke from a broader grounded theory study that included patients with a range of chronic conditions (stroke, heart disease, hypertension, diabetes). ${ }^{7,8}$ The purpose of this manuscript is to present an in-depth analysis of the impact of financial barriers specifically on stroke patients. Qualitative description is a methodology used to explore and describe the perspectives and views of patients in health-related research. It is the method of choice when seeking illustrative descriptions of phenomena. ${ }^{9}$ These studies typically use small samples of participants $(n=15-30)$ who are selected purposively to provide depth of information. ${ }^{10}$

All respondents had experienced a self-reported financial barrier in the previous year. Participants were recruited via signage in physician offices (including stroke neurology clinics) and pharmacies, as well as through research and clinical databases. We sampled participants for this study using a purposive sampling strategy: researchers preidentified strata that were important to have represented in the pool of participants (age, sex, Aboriginal status, number of chronic conditions). ${ }^{11}$ The study was approved by the University of Calgary's Conjoint Health Research Ethics Board.

\section{Data Collection and Analysis}

We collected data using semistructured face-to-face and telephone interviews focusing on participants' experiences of financial barriers. For this in-depth study of patients with a history of stroke, we explored the following domains within the interview: (1) participants' poststroke experiences; (2) participant experience of financial barriers; (3) perceived reasons for financial barriers; (4) health consequences of financial barriers; and (5) mechanisms for coping with financial barriers. Interviews were digitally recorded and transcribed verbatim by a professional transcriptionist.

Interview transcriptions were imported into NVivo 10 software (QSR International, Doncaster, Australia) for analysis purposes. We used a thematic analysis strategy using inductive grounded theory coding techniques. ${ }^{12,13}$ This is a process in which multiple reviewers (AG, DJTC) individually coded granular elements of each interview transcript into categories that were eventually collapsed into subsuming themes through an iterative process of discussion between the coders.

Consistent with recommended practices in qualitative research, we collected and analyzed data concurrently. ${ }^{14}$ This allowed for richer data collection as topics and themes identified in earlier interviews were explored in greater detail in subsequent interviews. Concurrent data collection and analysis also allowed us to continue sampling until saturation was reached in the broader study from which this cohort was selected. In qualitative research, theoretical saturation is deemed to be reached when enough interviews have been completed that no new substantive information is emerging from subsequent interviews. ${ }^{11}$ For this larger study, saturation was deemed to be met once three consecutive interviews did not yield any new substantive codes during initial open coding.

\section{ReSUlts}

Six participants with a history of stroke were interviewed over the course of a 4-month period. This included one man and five women, ages 42 to 73 years. Three participants were from ethnic minorities including one indigenous person. All participants were working before their stroke, but only two continued to work, whereas four had become unemployed following their stroke. The modified Rankin Score of stroke disability ${ }^{15}$ in our cohort ranged from 1 (no significant disability despite symptoms; able to carry out all usual duties and activities) to 4 (moderately severe disability; unable to walk without assistance and unable to attend to own bodily needs without assistance).

Several overarching concepts emerged from our analysis. These are briefly described and supported by verbatim quotes from participant interviews.

\section{Participants developed worsening financial circumstances as a direct consequence of their stroke-related disability.}

One of the participants used to run a small business, whereas another had worked as a health care professional before having a stroke. Although many of our participants likely would not have perceived financial barriers before their stroke, after the stroke all admitted to experiencing financial barriers. Many stated that their poststroke physical and cognitive impairments interfered directly with their ability to continue working and contributed to financial difficulties.

"I'm not as focussed, like I had a very senior position before and I worked there 29 years, but I find I'm not as focussed anymore... [I] was always very organized and very focussed and multitasking and I find that's just not quite the same." 
One participant who had immigrated to Canada and built up a small business ended up having to sell the business after two debilitating strokes, whereas another found herself unable to carry out the same high-level work:

"[Before the stroke], it was hard but I was working so then there was income. When I stopped working that was terrible, I didn't have any paycheques, nothing."

The unemployment and underemployment resulting from poststroke disability was often associated with a profound loss of self-worth and a loss of one's former identity.

"When you work you're whole, but when you get to the point of having to depend on other people for different things that you need ... It's like you don't become a whole person anymore. You become pieces. And if you don't have that piece to help you through that life you can't be whole. It's like you're lost."

2. Poststroke impairments and financial barriers influenced the mental and emotional health of participants, and were associated with notions of powerlessness and isolation.

Stroke-related complications, especially nonphysical ones such as cognitive or behavioural impairment, were described as highly isolating experiences for participants. They described struggling to get their loved ones to understand their disease and its consequences:

"I am a big guy, a lot of people who see me they just see the outside of me-a big, strong guy-especially my family members. I don't think they see how I struggle."

The financial barriers faced by the participants only served to exacerbate isolation. Participants noted that tight finances made even mundane social interactions and leisurely pursuits impossibilities. This, some claimed, resulted in a sharp decline in quality of life:

\footnotetext{
"And after [the stroke] when I was on government assistance ... I had to adjust the budget to the home... any financing for socializing and whatever, or entertainment, that was cut, so the quality of life went down."
}

The transition to disability and financial dependency was accompanied by a sense of hopelessness as well as feelings of anxiety and depression, including worsening of preexisting mental illness. One participant highlighted the powerlessness and loss of self-worth that was experienced with this dependency:

"Basically what happens is that you become dependent on people and that's what happens is that you lose yourself, and that's the way I feel right now-I lost myself."
Another participant stated:

"I live on $\$ 773$ a month and I can't go out to work which makes me upset and makes me more depressed. So it's like just a vicious cycle. And if I can't work, I can't make extra money and then my self-esteem goes down and my depression goes down and sometimes I get to suicide stage."

3. Participants struggled to access several key aspects of long-term poststroke care because of their financial barriers.

Despite receiving inpatient care with no costs to the patient at the time of their acute event, each participant identified challenges in accessing a number of key services following their discharge owing to financial barriers. The services participants had a difficult time accessing included allied health professional services like physiotherapy, occupational therapy, and psychology (for poststroke depression).

Participants expressed that accessing long-term physiotherapywhich is required on an ongoing basis by most patients who experience a moderately severe stroke — was a challenge:

"Well, they kinda just drop you like a hot potato. I do know that the physiotherapists here are really backed up and that it's very difficult to get into. The physiotherapy at the hospital, we don't have to pay for, but if you go to these private physio clinics ... it was $\$ 30$ a visit."

Another participant specified that they had a difficult time accessing occupational therapy:

"In my situation, it's not just the therapy for 4 months. No, because my work too is different from the other ones, right. So I need my therapy, it should be a continuous therapy. You can go home but you have to go here until you, it's, you need more, more, more, more hours, more, more focussed therapy."

Psychological support services was another area where participants faced financial barriers. One participant stated:

"[Counseling is] one of the things I quit doing because it was just getting so expensive. I went a couple times on my own dime 'cause I thought, you know, I'm worth that kind of money."

Participants also described difficulties accessing adequate home care and assistive equipment to accommodate their poststroke disability. Regarding assistive equipment, one participant stated:

"The doctor wanted me to get walking sticks for the support because when I've got the two braces, because I have no knees left, nothing left ... And he wanted me to get those but they're \$112, each. [Laughter] So it's forget that, that doesn't work." 
Medication expenses emerged as a consistent concern. Participants recognized this as an essential expense to prevent recurrent events and noted that they often had to keep other purchases in check to ensure that they could buy their medication:

"I can't complain that I'm paying because I have to take the medication. I am making sure for myself that I have the money before I go buy the medication."

However, the added expense burden of being prescribed brand-name versus generic medications was noted to be problematic. One person said:

"I'm on the generic of my high blood pressure pills. Before I was on [brand name antihypertensive] which is not covered and the doctor doesn't have any more cards so I can't get [it]... I had to go back to the generic.

We identified three subthemes relating to the patients' experiences of accessing long-term poststroke care, which are presented in further detail below.

(A) These participants struggled with juggling competing health-related expenses and faced challenging opportunity costs and trade-offs when accessing health services.

Competing health-related expenses included the cost of medication versus the cost of abiding by more expensive dietary regimens to manage stroke risk- such as fresh fruit and vegetables, unprocessed foods to meet low-salt and low-fat requirements, and low-glycemic-index sources of carbohydrate for diabetic control. In order to retain access to their medications, participants often ended up sacrificing on nutrition:

"Yes, low sodium for my hypertension, low fat for cholesterol and that. I try to manage as is possible so sometimes there's some money to afford that, sometimes not. It's about the priorities. It's sometimes really hard to keep the budget."

One participant had to use the local food bank to meet her nutritional needs. She struggled to find healthy dietary options and was forced to spend additional money on groceries:

\begin{abstract}
"Because my income has gone down I've gone to the food bank and basically you're getting starch and it's junk, but it is food so I can't say no... Sometimes the food that they give you is wrong and they give me stuff that I can't even eat, so I give it right back to them. So it's a waste of time sometimes... So by the time I pay my bills I think I have $\$ 50$ for groceries a month."
\end{abstract}

Some examples of difficult tradeoffs included sacrificing several hours of wages and bearing major costs of transportation and parking in order to attend critical health appointments:

"Oh, appointments, I lose, I have to be up there at quarter to three tomorrow which means I have to leave at two o'clock. You only get paid for the hours you work. There's no sick time."
Transportation issues were sometimes a direct consequence of the participant's inability to drive as a result of their stroke. One participant said:

"I can't drive so I gotta rely on public transportation ... they've cut back and changed the way people can get in for appointments."

(B) Participants were not aware of health care resources that they were eligible for, which might minimize the impact of their financial barriers.

In trying to meet their health-related expenses, each participant mentioned at least one strategy, including the use of community facilities like food banks, seeking out compassionate drug coverage plans, equipment loans, and donation programs. However, the same strategies were not shared by all participants. We noted that a strategy mentioned by one would be unknown to another. For instance, one participant applied for a compassionate drug coverage plan right after her stroke, so when asked about strokeprevention medication costs, said: "We rarely pay over $\$ 20$." On the other hand, another participant, who was an immigrant, only became aware of such programs after suffering a recurrent stroke:

"When I had a second stroke I applied for that special social [assistance] and [medication] was included in that ... [but] until [the] second stroke I paid all my medication."

Thus, in trying to advocate for their needs in light of their financial barriers, many participants came up against the challenge of inadequate knowledge of resources available to them, which may have mitigated the impact of the financial barriers they experienced. This meant that they risked paying for certain services that they could have had covered through another means. Participants found that they had to independently seek out this essential health resource knowledge, as expressed by one of our participants who had moved from a different province and struggled to obtain a health care card needed to access publicly covered services:

“I still don't know all the resources. I've found coming from [another province] to Alberta, it was the first thing I did. In some ways it was really bad because everything is so split up here. Basically for medical, nobody said that I had to do, go to the registry office to get my medical card. Nobody told me I had to do this, nobody. It's like you have to learn this and it's really difficult and they don't make it easy."

A participant who was formerly a health care worker highlighted the importance of this barrier:

"I have trouble myself and I am a [health care professional] ... how much more those people that are not."

(C) Participants were hesitant to discuss their financial barriers with their family members and their physicians. 
Participants expressed reluctance in reaching out to their children and other loved ones about their financial struggles. One of the reasons was the challenge of finding themselves in a position of depending on others, having previously been carers and providers:

"I don't like to bother them, my family. It's hard to ask, you know it's embarrassing. Whole life I took care about everything and after stroke it's like no, it's hard... Now I'm the one needing help and it's very difficult for me to say I need help 'cause I've been helping all the time."

Participants also expressed reluctance in disclosing their financial barriers to their physicians; some felt disconnected from their doctors while trying to communicate the impact of these barriers on their lives. When asked about whether his family physician knew about his financial situation, one participant replied:

"No. It's not something I like to hang around my neck: 'Help me, I'm poor'. I have my pride."

\section{DisCUSSION}

In this qualitative descriptive pilot study of stroke patients with financial barriers, we noted several barriers faced by such patients that interfere with their health and recovery following acute stroke. Similar to prior studies on the social consequences of stroke in working-age adults, our participants described new or worsening financial barriers following their stroke, with a negative impact on their family relationships and leisure activities. ${ }^{16}$ Even publicly insured services such as physician appointments posed difficult choices for these participants because they carried substantial indirect associated costs such as transportation, parking, and lost income from hourly work. In the United States, competing priorities have been found to be a key contributory factor in lower socioeconomic status patients delaying or avoiding medical care appointments. ${ }^{17}$

Given the lack of a universal pharmaceutical insurance plan, medication costs are known to be a challenge for Canadian patients with cardiovascular-related chronic diseases. ${ }^{5}$ Among our participants, we found this was indeed a considerable burden. We also found that noninsured allied health care services (such as physiotherapy, occupational therapy, and psychology) may be inaccessible because of cost. However, cost is unlikely to be the only factor influencing access to such services, as a previous study of acute stroke patients in Ontario found that patients in the lowest income quintile were less likely than those in the highest to receive inpatient rehabilitation services poststroke, which patients do not have to pay for. ${ }^{18}$

Our interviews indicate that patients may be reticent to self-disclose their socioeconomic challenges to their physicians. Furthermore, the experience of stroke was accompanied by a sense of isolation, lower self-worth, and dashed hopes for participants who had been breadwinners and sources of strength for their families, and now struggled with a new state of dependency. These descriptions are consistent with the "biographical disruption" and impact on sense of self that chronic illnesses such as stroke have been associated with in prior studies. ${ }^{19,20}$ This notion of powerlessness has been found to extend to the interactions of patients with their health care professionals, and helps contextualize our participants' reluctance to disclose their financial barriers. ${ }^{21,22}$

Therefore, if stroke physicians and allied health professionals do not explicitly ask about their patients' financial situation or discuss medication-associated expenses, they may remain ignorant of the depth of these struggles. Clinicians may be falsely reassured by the presence of apparent social supports for their patients-for example, having a spouse or adult children-but, as our interviews revealed, this does not mean that such supports negate the impact of financial barriers. Furthermore, our interviews highlighted the issue of inadequate health resource knowledge among patients. Even when seeking out such knowledge, many participants struggled with the complexity of health information. In other words, just because there is some kind of special accommodation or funding available, physicians cannot assume their patients will come to know about it and will access it. Previous studies have identified inadequacies in information provision in stroke care regarding resources for stroke patients and their informal caregivers. ${ }^{23-25}$

Given that our study was a pilot, it was limited by the small number of participants sampled. Our sample was unusually diverse in comparison to the general population-half of our participants represented ethnic minorities and all but one were women. The diverse ethnic representation in our study is highly relevant to our objective of assessing barriers in stroke care. North American minorities are known to have higher stroke risk, stroke recurrence at an earlier age, and, for some groups, more severe strokes than Caucasians. ${ }^{26}$ They also appear to be confronted with both financial and nonfinancial barriers, ${ }^{27}$ with a recent Canadian study of patients with cardiovascular-related chronic conditions finding that non-Caucasian race was significantly associated with reporting financial barriers to care. ${ }^{5}$ Despite this diversity, we did not have representation from all who may conceivably have had financial barriers; for instance, none of the participants was homeless, so the financial barriers experienced by our participants are potentially a milder reflection of those experienced by Canadians in the lowest socioeconomic strata. Furthermore, although the broader study sample was continued to saturation, we did not continue to enroll patients until the stroke cohort was saturated. This work is therefore an exploratory pilot and will set the stage for future qualitative and quantitative studies in this area. In particular, further characterization of the nature and extent of deficits in knowledge related to potential resources available to this population could help inform educational interventions as part of acute stroke care to address some of the accessibility challenges identified. The extent of physician knowledge of financial barriers and patient disclosure regarding financial barriers is also an important avenue of further study because this may facilitate alternative strategies for the early identification and management of such barriers as part of the care pathway.

\section{ConClusions}

In the quintessential pursuit of optimizing in-hospital processes for acute stroke care, Canadian stroke systems must not lose sight of the mountain of disability that many patients are left to climb afterwards - one that becomes increasingly insurmountable when financial barriers are present. Our small qualitative pilot study has identified several factors experienced by stroke 
patients with financial barriers that merit further exploration as potentially contributing to differences in long-term stroke outcomes among socioeconomic strata. We found that individuals' perceptions of their financial constraints were particularly impactful, not just their absolute household income or some other measure of socioeconomic status. In particular, patients who are especially susceptible to perceiving a negative impact from financial barriers may suffer from feelings of isolation and powerlessness owing to poststroke dependency. They also perceive challenges to access various aspects of long-term poststroke care - particularly medications and allied-health services - that may be exacerbated by inadequate resource knowledge and a reticence to disclose financial difficulties to their health care providers. "Time is brain" in acute stroke, but beyond those first few hours, in the long-term journey of rehabilitation and secondary prevention, it would seem that "money is brain," too.

\section{ACKNOWLEDGEMENTS AND FUNDING}

The authors thank our participants for their candid participation in this study. We are grateful for the assistance of Pamela Leblanc and Jo Anne Plested for helping with interviews and Sean Dukelow for assisting with participant recruitment.

This study was funded by Alberta Innovates-Health Solutions via a clinician fellowship to DJTC and through a team grant to the Interdisciplinary Chronic Disease Collaboration.

\section{Disclosures}

$\mathrm{MDH}$ has the following disclosures: Medtronic (Covidien), grant recipient, grant to the University of Calgary for the ESCAPE trial; Boehringer Ingelheim Canada, grant recipient, grant to the University of Calgary for Education in the QuiCR Stroke program; Medtronic (Covidien), grant recipient, grant to the University of Calgary for the HERMES collaboration; board of directors, QuickFlo Health Inc., no compensation was received. AG has the following disclosures: SnapDx, cofounder and advisor, Stocks; The Self-Care People, Advisor, stock options; The Rounds.ca, advisor, gift; The Rounds.ca, advisor, stock options. KK-S, BJM, and DJTC do not have anything to disclose.

\section{REFERENCES}

1. Chen R, McKevitt C, Rudd AG, Wolfe CD. Socioeconomic deprivation and survival after stroke: findings from the prospective South London Stroke Register of 1995 to 2011. Stroke. 2014;45:217-23.

2. Kapral MK, Fang J, Chan C, et al. Neighborhood income and stroke care and outcomes. Neurology. 2012;79:1200-7.

3. Kimball MM, Neal D, Waters MF, Hoh BL. Race and income disparity in ischemic stroke care: nationwide inpatient sample database, 2002 to 2008. J Stroke Cerebrovasc Dis. 2014; 23:17-24
4. Huang K, Khan N, Kwan A, Fang J, Yun L, Kapral MK. Socioeconomic status and care after stroke: results from the Registry of the Canadian Stroke Network. Stroke. 2013;44:477-82.

5. Campbell DJ, King-Shier K, Hemmelgarn BR, et al. Self-reported financial barriers to care among patients with cardiovascularrelated chronic conditions. Health Rep. 2014;25:3-12.

6. Macdonald ME, Chalk C. Not just numbers: qualitative research and the clinical neurosciences. Can J Neurol Sci. 2011;38:195-6.

7. Campbell D, Manns B, Hemmelgarn B, Sanmartin C, King-Shier K. The development of a conceptual framework for understanding financial barriers to care for patients with cardiovascularrelated chronic disease: a protocol for a grounded theory (qualitative) study. CMAJ Open. 2016;8:E304-8.

8. Campbell D, Manns B, Leblanc P, Hemmelgarn B, Sanmartin C, King-Shier K. (In Press). Finding resiliency in the face of financial barriers: Development of a conceptual framework for people with cardiovascular-related chronic disease. Medicine.

9. Sandelowski M. Whatever happened to qualitative description? Res Nurs Health. 2000;23:334-40.

10. Morse J. Designing funded qualitative research. In: Denzin N, Lincoln Y, editors. Handbook of qualitative research. Thousand Oaks, CA: Sage; 1994, p. 220-35.

11. Sandelowski M. Sample size in qualitative research. Res Nurs Health. 1995;18:179-83.

12. Charmaz K. Constructing grounded theory. Thousand Oaks, CA: Sage Publications; 2006.

13. Strauss AL, Corbin JM. Basics of qualitative research: techniques and procedures for developing grounded theory, 2nd ed. Thousand Oaks, CA: Sage Publications; 1998.

14. Bowen GA. Naturalistic inquiry and the saturation concept: a research note. Qual Res. 2008;8:137-52.

15. Rankin J. Cerebral vascular accidents in patients over the age of 60 . II. Prognosis. Scott Med J. 1957;2:200-15.

16. Daniel K, Wolfe CD, Busch MA, McKevitt C. What are the social consequences of stroke for working-aged adults? A systematic review. Stroke. 2009;40:e431-40.

17. Diamant AL, Hays RD, Morales LS, et al. Delays and unmet need for health care among adult primary care patients in a restructured urban public health system. Am J Public Health. 2004;94:783-9.

18. Kapral MK, Wang H, Mamdani M, Tu JV. Effect of socioeconomic status on treatment and mortality after stroke. Stroke. 2002;33:268-73.

19. Bury M. Chronic illness as biographical disruption. Sociol Health Illn. 1982;4:167-82.

20. Ellis-Hill CS, Horn S. Change in identity and self-concept: a new theoretical approach to recovery following a stroke. Clin Rehabil. 2000;14:279-87.

21. Tanner D. Sustaining the self in later life: supporting older people in the community. Ageing Soc. 2001;21:255-78.

22. van Ryn M, Burke J. The effect of patient race and socio-economic status on physicians' perceptions of patients. Soc Sci Med. 2000;50:813-28.

23. Low JT, Payne S, Roderick P. The impact of stroke on informal carers: a literature review. Soc Sci Med. 1999;49:711-25.

24. Kerr SM, Smith LN. Stroke: an exploration of the experience of informal caregiving. Clin Rehabil. 2001;15:428-36.

25. Mold F, McKevitt C, Wolfe C. A review and commentary of the social factors which influence stroke care: issues of inequality in qualitative literature. Health Soc Care Commun. 2003;11:405-14.

26. Trimble B, Morgenstern LB. Stroke in minorities. Neurol Clin. 2008;26:1177-90; xi.

27. Scheppers E, van Dongen E, Dekker J, Geertzen J, Dekker J. Potential barriers to the use of health services among ethnic minorities: a review. Fam Pract. 2006;23:325-48. 